\title{
The Application of RAROC in Performance Evaluation of Commercial Banks in China: Literature Review
}

\author{
Fan Xia \\ School of Economics and Management, Hubei University of Technology, Wuhan, 430064, China \\ xiafan_Zoe@163.com
}

Keywords: Risk-Adjusted Return on Capital (RAROC), Commercial Banks, Performance evaluation.

\begin{abstract}
RAROC has been introduced into financial institution groups for performance evaluation and risk management, with the increasing of risk awareness in domestic financial institution groups. RAROC in commercial banks is mainly used for capital allocation, risk management, loan pricing, and even performance evaluation. RAROC as an overall performance evaluation method and risk management approach, taking the balance of risk-profit into consideration, has carried out extensive theoretical research in China. Based on the studies of RAROC in performance evaluation, this paper analyses the current application, research extent and problems in performance evaluation of RAROC in commercial banks in China, and puts forward the proposal to improve the system, according to the recent operation of domestic market and financial institution groups.
\end{abstract}

\section{Introduction}

In recent years, China's economic development has entered a new stage. With the proposal of Basel II, the domestic financial institution groups began to doubt the integrity of risk consideration, and have a more profound understanding of risks, especially when it comes to commercial banks. Since there are various kinds of risks existing in commercial banks business, such as interest risk and credit risk, it is inaccurate and limited to judge the competitive status of commercial banks by measuring the performance according to the traditional indexes. At present, commercial banks in China have shifted from pursuing profit maximization to shareholders' value maximization as a more effective business target. As the expansion of traditional scale and reflecting business performance by accounting subjects (such as the balance sheet) can't meet the real needs, a comprehensive performance evaluation system has to be established in order to achieve this goal. Therefore, Risk-Adjusted Return on Capital (RAROC) gradually came into financial institution groups in China from the theoretical study of Western commercial banks, and even extended to non-financial institution groups. A large amount of literature emerged into research field, which had significant influence on the understanding and implementing this special management technique.

Currently, commercial banks in China methods for performance evaluation are Balanced Scorecard, Key Performance Indicator (KPI), where the most important indexes of KPI performance management are EVA (Economic Value Added) and RAROC (Risk Adjustment Return on Capital). At the current stage, EVA is more widely used than RAROC since RAROC is still in the early stages of research and application, which needs more theoretical support. EVA refers to the economic value added, which can effectively avoid the impact of different accounting standards and accounting operation on traditional indexes. It is the operation return excluding the capital cost, in other words, is the balance of adjusted after-tax operation profit and capital cost. RAROC calculates the capital allocation based on the risk adjusted rate of capital return. The method of allocating economic capital is predicting the non-expected losses based on different types of risks. There are different methods for the three non-systemic risks: the internal rating method suits for credit risk; the standard method and internal model method can be used for market risk; index method, standard method and internal measure method are eligible for operation risk. 
Compared to the EVA index, RAROC indicators can consider the risk more comprehensively, which is way better than EVA indicators. Therefore, the RAROC indicators have greatly improved the emphasis on accounting subjects (static data), overcoming the relative misplaced problems reflected in the profitability and risk costs of traditional performance evaluation in different periods, and realized the unity of business objectives and performance evaluation. The use of RAROC can compare the RAROC of branches at all levels, of various business, of the products, and even of each employee, which can improve the scientificity and comparability of the performance appraisal. Based on the practical significance of the application of RAROC in the performance evaluation of financial institution groups in China, the domestic scholars have carried out a series of research and empirical analysis from different fields, different directions and different measurement methods of each factor in the models, and have made detailed descriptions of the conclusions, as well as put forward the relevant recommendations, and pointed out the limitations of this study. Therefore, it is necessary to review and to summarize the current literature systematically.

Therefore, the purpose of this paper is to summarize the research literature of RAROC in China and try to answer the following questions: Firstly, what is RAROC risk management technology? What is its calculation method and function? What is the necessity of introducing RAROC in China? Secondly, how can China's commercial banks use the RAROC model for performance evaluation and risk management? Third, what are the similarities in these studies? What different conclusions we can get for resolving the same problem? What improvement can we get based on the discovery of predecessors? How is RAROC implemented in China? What are the limitations of research, the need of improvement and the prospects of it? And we will try to make feasible prediction of the future development of RAROC in China.

\section{Development}

RAROC (Risk Adjusted Return on Capital) refers to the risk adjusted capital earnings. The method was proposed by Bank Trust in the 1970s with the initial thought of measuring the risk of bank credit portfolio and the number of necessary shares to limit exposure at a specific loss rate. Based on the risk-adjusted economic capital of the bank performance management method (RAPM), Merton and Perold in 1993 first put forward the concept of "Marginal Risk Capital". Zaik (1996), James (1996) and Matten (2000) proposed the three main contents of the economic capital framework: economic capital measurement, economic capital allocation and performance evaluation based on risk - adjusted.

In addition, the implementation of RAROC expanded gradually from commercial banks to the insurance industry, and even to non-financial institution groups. Marcel Prokopczuk. (2006) applied the RAROC method to quantification of risk in the power industry as well.

Beginning China's financial institution groups, including non-financial institution groups, pay more attentions to risk management in business operations in recent years, and the traditional profitability indicators, including equity return (ROE) and asset yield (ROA) did not take risks as a factor. Therefore, the western commercial banks gradually started to use the profitability indicators with the consideration of risks (risk adjustment gains). RAPM (Risk Adjusted Performance Measurement) can overcome the shortcomings of management objectives not fully reflecting the risk cost in traditional performance evaluation, and changed the operation methods of banks who used to ignore risks and blindly pursue profit.

The two main applications of RAROC risk management technology are from these two aspects: as for performance evaluation, China's commercial banks and other financial institution groups usually focus on risk or profit indicators and the relationship between risk and income when it comes to appraise all the branches and business management sectors at all levels; as for risk management, Chinese scholars mainly apply RAROC model in optimizing the capital allocation, loan pricing and other researches.

The core idea of RAROC is to quantify future predictable risk losses into current costs, adjust current earnings, measure risk-adjusted returns, and to make capital reserves for unintended losses in order to measure the efficiency of capital use, and further link the risks and income of banks. 
This can refrain the commercial banks from only setting profit maximization as its ultimate goal, while ignoring the impact risks can bring to the bank in various business operations.

RAROC calculation formula can be expressed as:

$$
R A R O C=\frac{R-O E-E L}{C a R}
$$

Where the Revenue $(\mathrm{R})$ refers to the non-interest income, such as price differences of financial institution groups assets. Operation expenditure refers to money paid by financial institution groups while conducting the asset and liability management from resources, advance payment and regular business charges. Expected loss demonstrates the amount of loss financial institution groups get due to probability event occurred during the normal operation process. Usually financial institution groups will set reserve fund for this part of the loss in advance, and the venture capital is the minimum capital requirement that the bank corresponds to the risk to be borne by it.

According to Basel II, risk synthesis RAROC can be expressed as:

$$
\left\{\begin{array}{l}
C a R=\text { creditCaR }+ \text { marketCaR }+ \text { operationCaR } \\
R A R O C=\frac{R-O E-E L}{C a R}
\end{array}\right.
$$

The application of RAROC in performance evaluation can be done on the stage of head office, branches, product line, account managers, individual customers and single business level. Essentially, the RAROC indicator measures the use benefit of economic capital. For the performance evaluation of the micro-evaluation perspective, RAROC evaluates the performance of each business personnel and thus determines the level of compensation, yet it is prone to be incentive incompatible. The solution is to set EVA as the objective function, under the constraints of information asymmetry, using RAROC indicators to calculate. For the performance evaluation of the product line, the basic idea is to use historical data to calculate the economic profit and capital expected cost, then calculate the risk adjustment capital gains (economic profit and capital expected cost ratio), and ultimately align income. Certainly, except for the interior of the organization, the regulatory authorities of financial institution groups also need to make decisions through performance evaluation.

\section{Research on Domestic RAROC Model: From the Perspective of Performance Evaluation}

For special enterprises with high risk and high standard such as commercial banks, people pay particular attention to the measurement of risk in the performance evaluation of their operation and management. The performance evaluation of traditional commercial banks depends on financial indicators, for instance, the return on assets (ROA) in DuPont Analysis. Financial indicators do not take into account risk factors. Accounting information is established by static book information and is difficult to be related to real risk. Therefore, RAROC system emerged.

RAROC performance evaluation is mainly based on the traditional index evaluation system with traditional indicators evaluating the bank profitability, which includes return on equity (ROE), return on asset (ROA), along with the introduction of Western commercial banks' RAROC performance evaluation methods, and combined with China's financial market environment to establish the RAROC performance evaluation framework for China market environment. The existing literature elaborate and analyze the concept and essence of RAROC, the advantages of traditional indicators, the practical application effect, and the application limitations and the development.

Domestically, both the in-depth study of the functional operating model of RAROC and the empirical analysis of RAROC applications have relatively more innovative results. From a general review, the research direction of Chinese scholars is divided into two parts by RAROC: performance evaluation and risk management. In terms of risk management, according to the different risks faced by commercial banks, it is further refined into the application of capital 
allocation, risk preference and loan pricing. This paper explores the research process and conclusions of RAROC from the perspective of performance evaluation, and finds out the innovation and limitation of them, and further summarizes the research literature of it.

First of all, Zhang et al. (2010) analyzed the concept of RAROC in "RAROC and Commercial Bank Performance Evaluation", and discussed the role of ROROC system in commercial bank performance evaluation from three aspects. On the level of micro evaluation, the RAROC model, which is different from the traditional financial statement evaluation developed on the head office, focuses more on evaluating the overall situation from the perspectives of the head office, the branches, the product lines, the client manager level, and the single business point of a single customer.

In terms of the aspects of different product lines and various institutions, here presents the riskadjusted rate of return, which means calculating the risk-adjusted rate of return of each product line and equipping higher capital on the product lines with higher risk-adjusted rate of return and ultimately align the unit risk revenue consistency on each product line. ${ }^{[1]}$ As for the supervision of capital adequacy ratio, the amending RAROC factor $A^{\prime}$ (the reserve fund for maintaining the capital adequacy ratio) provides a lower empirical limit of the necessary profit ${ }^{[1]}$.

In recent years, with the sharp changes in financial environment and the tremendous innovations of financial business, the scope of commercial banks implementing RAROC evaluation system is expanding along the way, yet various difficulties will be encountered during the process of actual use. Domestic research literature conduct empirical researches from the RAROC model itself, and point out the corresponding solution and model improvement in allusion to its application effect. The internal control and compliance department of Industrial and Commercial Bank of China, Guangxi Branch (2008), conducted an empirical analysis on the internal control and compliance management based on the annual report data of three branches of a commercial bank at the end of 2007 and came up with three practical significance of the application of RAROC evaluation system, which are highlighting the principle of risk control to optimize the allocation of economic capital; improving the economic performance appraisal mechanism; promoting economic model transformation.

Wang Jiahua et al. (2011) creatively analyzed the situation when applying the RAROC evaluation method into performance audit, proceeded with the challenge of financial environment changes and financial innovation to the audit of commercial banks, and concluded the performance audit evaluation index from three perspectives, which are commercial bank comprehensive risk management audit, capital allocation efficiency audit, and business performance audit, with which can construct rationalization audit system. Moreover, they established the analytic framework of commercial bank performance audit evaluation based on the RAROC and proposed three approaches to solve the problem, which are talent training, information database construction and establishment of performance evaluation standard and system.

As for improving the operational model of RAROC in domestic commercial banks, in accordance with the bank operational strategy, financial and non-financial indicators, Kongninging (2007) built the comprehensive performance evaluation framework based on the ROE traditional performance evaluation system of commercial banks, combined with external business environment analysis (from market, product, customer, channel, competitor), along with strategic analysis and internal performance value and the RAROC shareholders value changes analysis, in order to achieve multiple performance balance, and to meet the bank management needs under current domestic market conditions, which can provide a scientific way to measure performance.

In the aspect of improving the calculating process of the model, Fang Yi et al. (2007) introduced CVaR into RAROC for performance evaluation, and conducted the empirical analysis on fund performance evaluation by utilizing the Bootstrap method, which finally enabled them to financial institution groups out that $\mathrm{CVaR}$ is more close to the actual situation compared with VaR since VaR is more limited to some extend. Dou Erxiang (2011) proposed that the TailVaR function is more reliable and accurate than the VaR, which can make the RAROC model measure the operational 
risk and efficiency of the financial institution groups in China from the whole, and help investors on investment decision-making ${ }^{[17]}$.

\section{Conclusion}

In recent years, the performance evaluation system in domestic commercial banks, and other aspects of financial institution groups, have experienced the change from simply pursuing profit maximization to focusing on risk factors. Applying RAROC into financial institution groups has revolutionary significance for enhancing current economic condition in China. Starting from commercial banks in financial institution groups, the RAROC model has been penetrated into all kinds of services and even insurance companies. Replacing traditional indexes with RAROC has preliminary effect since RAROC has played a crucial role in performance evaluation and risk management in domestic financial institution groups, which has avoided the shortcoming of ignoring the risk, enabled risk factors to be measured with the combination with financial and nonfinancial indexes, and also done well for optimizing the capital allocation of financial institution groups and hierarchical performance evaluation of financial institution groups, while it is still at the preliminary stage. As for banks in China, under the current trend of interest rate liberalization, the mixed operation of bank is gradually liberalized. However, the market still lacks of mechanism and business, a comprehensive RAROC performance evaluation system needs to be built, which not only promotes the traditional concept of commercial banks in China, but also challenges the process of overcoming technical problems.

In the view of the application of RAROC model in commercial banks in China, a large number of literature have made in-depth understanding of RAROC and found the practical significance of applying RAROC into market. The research purpose is divided into three aspects: model research, the establishment of suitable comprehensive performance evaluation system for China, and the model improvement research.

Existing research and analysis of China RAROC model pointed out that RAROC model can be applied to commercial banks in China, head office, branches, product lines, customer and other levels of performance to complete comprehensive evaluation, but since the actual market information system conditions are not perfect, RAROC implemented in a single business with a single customer is still in an ideal state. Therefore, based on the current level of research in China, in order to implement the RAROC model, it not only needs a strong information data system, but also the ability to overcome technical problems, and to develop effective mathematical formulas. The idea will never be realized if it is lack of statistical theory as a backup. As the attempt to establish a comprehensive performance evaluation RAROC system applicable to the Chinese market environment, the study pointed out that RAROC should under the guidance of commercial banks' strategy, synthesize financial and non-financial indexes and construct a comprehensive evaluation system, mainly by adjusting the cost of risk adjustment configuration, the corresponding cost of income, so that the unit income can be consistent, and taking into account the risk and the relationship between income. However, the development of a comprehensive performance evaluation system is difficult to overcome the limitations of practical problems, the introduction of RAROC performance evaluation index system is only a start. In the aspect of model improvement, the domestic experts introduced various indexes into RAROC, and make the actual calculation and comparison. As the actual situation is changing, the risk is probably asymmetric, bias, fat tail and so on. The traditional index may not meet subadditivity, continuity and inadequacy which will lead to failure. Hence the method of measuring the risk capital is studied, and the RAROC model which is more suitable for the actual complex market environment is constructed.

Traditional performance evaluations emphasize the importance of financial analysis instead of taking into the non-financial indexes account, which is lack of strategies and cannot reflect the real situation well. The RAROC model not only takes the risk indicators into consideration, but also can thoroughly analyze the origin, nature and impact of the risks, where the performance of commercial banks can be accurately analyzed. The RAROC model analyses the expected loss-adjusted earnings 
and economic capital, which can be reflected in the adjusted profitability of the risk factor, where the more rational performance evaluation can reflect the overall situation better than others.

It can be found in the RAROC theoretical analysis and empirical applications that there are still some deficiencies in China's market and financial institution groups. First of all, the data information system is imperfect. Application of RAROC has higher requirements on information systems management, the lack of prerequisite leads to the result that RAROC applications would simply stay on the surface, and it is difficult to deepen the application of RAROC. Therefore, to improve the efficiency of data search can help scholars for empirical studies. Secondly, China's RAROC theoretical basis and mathematical proof is not sound and solid, which means that it will be hard to analyze the general direction or to describe the theories. Thirdly, the lack of professional quality of personnel training leads to the incentive incompatibility problems which need to be resolved. Therefore, it is clear to see that RAROC has huge potential to develop in Chinese market. The RAROC risk management technology has not only limited to the financial institution groups, but gradually extends outward. There are successful cases in of non-financial institution groups who introduced the RORAC system into the process of performance evaluation and risk management.

In summary, although the RAROC model in China is relatively immature on the aspects of implementation and research, the current developing trend of interest rate liberalization and mixed business operations are similar with the one of western countries in the 20th century. Foreign literature researches and history experience have a reference to the development of RAROC in China. To maximize the advantages of RAROC in terms of performance evaluation, the establishment of a comprehensive performance evaluation framework based on RAROC is an inevitable trend in which the primary task of financial institution groups is to abandon the traditional concept, to face the risks in the right way, to consider risks, to deal with risks, and take strategic planning seriously, identify strategic objectives and translate them into measurable specific targets and adjust them in a timely manner. Foreign literature theories are great references for mathematical proof of RAROC implementation in China, where solid theoretical basis of mathematics and a large number of mathematical models for empirical calculations are required, in order to build suitable models for domestic situations. As for conditional construction, the market needs to establish a strong data information system, so that the data can be more comprehensive. The country needs to strengthen the training of professionals with more technical training. So as to improve the RAROC model, to maximize the value of the shareholders of the business objectives, to maximize economic efficiency. As a result, the performance evaluation can be perfected and China's financial institution groups, even the economic system can be promoted in the coming future.

\section{References}

[1] Zhang Lu, Liu Hu, RAROC and Commercial Bank Performance Evaluation [J], Finance and Finance - Financial Overview, 2010

[2] Kong Ningning, To build RAROC as the core of the commercial bank comprehensive performance evaluation framework [J], Finance and Economics, 2007.4

[3] Wang Jiahua, Zhang Wei, Liu Zhiyou, RAROC technology based on commercial bank performance audit research [J], finance and trade economy, 2011 fifth period

[4] FANG Yi, ZHANG Yishan, Comparative study of CaR, VaR applied in RAROC [J], Mathematical Statistics and Management, Vol. 26, No. 1, January 2007

[5] Research on the effect of RAROC model on the internal control management of commercial banks [J]; Guangxi Finance Research, 2008, No. 10, China Industrial and Commercial Bank of China, Guangxi Branch, Internal Control and Compliance Department,

[6] Bian Junjie, Application of RAROC in capital allocation of China's commercial banks [J], Guizhou University of Finance and Economics: Economics and Management - Finance, 2008 No. 2 
[7] Zhang Xuefeng, Zhang Changhai, Application of RAROC in capital allocation of China's commercial banks [J], economist: economy and observation, 2007 the first period

[8] Xu Min, He Lei, Commercial Banks Using RAROC to Optimize Credit Resource Allocation [J], HAINAN FINANCE: Economic Management, Issue 10, 2012

[9] Chen Liang, Zhang Zhongyong, M-V commercial capital allocation model based on RAROC [J], Journal of Jiangxi University of Finance and Economics, No.3, 2014

[10] Design and Evaluation of Comprehensive Risk Management Model: Based on RAROC [J], International Finance Research: Theory, 2005.3

[11] Fan Dongjun, RAROC-based commercial bank risk tolerance calculation [J], Inner Mongolia University of Finance and Economics, 2008 No. 3

[12] Ma Jiao, Zhang Zhixiang, Credit rate under the marketization of commercial banks credit risk management model improvement - based on RAROC model [J], modern economic information, 2014

[13] Zhou Kai, RAROC-based commercial bank loan pricing model research [J], World Economic and Political Forum, 2008 No. 2

[14] Peng Jiangang, Lv Zhihua, Zhang Lihan, Tu Haibo, Bank loan pricing comparative advantage principle and mathematical proof based on RAROC [J], Hunan University (Natural Science Edition), 2007 No. 34 No. 12

[15] Xue Feng, Sun Jin, Bank loan pricing based on RAROC [J], Economic Jingwei, 2009 No. 6

[16] Meng Caiyun, Interest rate market under the commercial bank loan pricing ability of China based on the RAROC model of the empirical study of loan pricing [J], theoretical discussion, the fourth period in 2014

[17] Dou Erxiang, Xiong Canbin, RAROC-based risk analysis and risk analysis of China's financial institution groups [J], International Finance Research: Banking Research, 2011.1

[18] Liang Ling, Wu Dan, RAROC loan risk pricing model and its credit boundary [J], Systems Engineering, Vol. 26, No. 7

[19] Liu Zhenhua, Xie Chi, RAROC model based on the commercial bank credit line [J], Economic Management: Accounting and Finance, 2012 the 12th

[20] Huang Jixian, Gu Liu Liu, RAROC model loan pricing and bank pricing comparison [J], Financial Forum, 2014, No. 5

[21] Pan Lingyao, Jiang Da, RAROC loan pricing model based on corporate loan [J], Systems Engineering, Vol. 32, No. 3 